\title{
Climate Change and Agricultural Transformation in Shigar Valley, Gilgit-Baltistan, Pakistan: A Commune-Scientific Perception
}

\author{
Shafeeqa Batool ${ }^{1}$, Tika Khan ${ }^{1 *}$, Rehmat Karim², Muhammad Zafar ${ }^{2}$, Sultan Ahmed ${ }^{3}$ \\ ${ }^{1}$ Department of Biological Sciences, Karakoram International University, Gilgit-Baltistan, Pakistan \\ ${ }^{2}$ Department of Environmental Science, Karakoram International University, Gilgit-Baltistan, Pakistan \\ ${ }^{3}$ Department of Medica and Communication Science, Karakoram International University, Gilgit, Pakistan
}

\begin{abstract}
Climatic change is no more a theoretical paradigm but a scientific fact now. Its men fed incubation period has over and symptoms are evident not only across highland glaciated areas like Shigar Valley, Baltistan and rest of the world but also downstream areas. Communities living in Shigar Valley are agro-pastoral and depend on snow and glacier meld water for agriculture and other domestic uses. Their principal agriculture produce consists upon wheat, buck wheat and barley. Study revealed that over the last thirty years, inhabitants have gone through a transition towards new adaptation approaches caused by climate change in the valley. With a decline and decrease in glacial mass and agricultural produce local inhabitants seek more employments and off-farm activities rather than spending their time on fields. Temperature has increased and experienced throughout the year has winter has become short and mild followed by warmer prolonged summer experiencing $40^{\circ} \mathrm{C}+$ hotness which previous generations has never experienced in their life time. A marking shift of 7-15 days of flowering time is visible. Rainfall has highly increased in its intensity during spring followed by winter. Snowfall has a marking shift from little fall in winter towards heavy fall in spring followed by an increase in monsoon flooding, floral diseases and fuel consumption. Vegetation cover has declined more near village as compared to pastures. Crop sowing, harvesting and snow melt periods have prolonged. Avian, mammalian and herpeto fauna have declined in terms of their species richness and population equally. A change impacting rural livelihood and food insecurity is visible. In a prevailing situation innovative folk wisdom grounded mitigation and adaptation strategies are needed.
\end{abstract}

Keywords- Agro-pastoral, agricultural produce, agricultural yield, adaptation strategies, livelihood, global warming.

\section{INTRODUCTION}

Global climate change is a shift in the "average weather" that a given region experiences over a long period of time (30 years or so) (Steffensen et al. 2008). Such a change enforced by the increases in temperature will have considerable impact on various socio-economic sectors e.g., water, agriculture, health, forestry, biodiversity etc. and Gilgit-Baltistan is not an exception to these changes (Parry et al., 2004).

Climate change is a major threat for sustainable development, therefore, global response towards increasing environmental challenges such as climate change put more emphasis on addressing both the issues simultaneously (Hanjra and Qureshi, 2010). As our knowledge and experience of disaster risk reduction, impacting poverty and Climate Change Adaptation grows it has become increasingly important to understand local climate change knowledge, perceptions of adaptation, how communities manage the impact of climate change and use of indigenous resources to mitigate negative impacts and improving socioecological health (Heltberg et al. 2009). In context of Gilgit-Baltistan, Seabuckthorn is a multipurpose rich resource to meet the acute challenges of climate change and poverty reduction impacting vulnerability of climate change (Gregory et al. 2005).

People in Shigar valley largely rely on natural resources and are traditionally agro-pastoralist in nature. It also faces issue of availability of arable land for agriculture. Due to uneven high, rocky and steep terrains cannot be used for scalable agriculture. Crops are grown on terraced slopes or alluvial plains. Communities living in Shigar Valley are agropastoral and depend on snow and glacier meld water for agriculture and other domestic uses. Their principal agriculture produce consists upon wheat, buck wheat and barley. Study revealed that over the last thirty years, inhabitants have gone through a transition towards new 
adaptation approaches caused by climate change in the valley. Dried apricots and apricot kernel are principal items. Other agri products and fruits include fresh and dried apple, cherry, grape, mulberry and pear.

Shigar valley in district Skardu, Baltistan is rich for its natural resources including an array of glaciers, vegetation, streams and unique biodiversity. Over the last several years, the Shigar valley is transforming into a town and during the course several climatic factors have changed and put challenges before inhabitants. Traditional farming has changed into semi mechanized exotic tools and techniques, irrigation receives insufficient water, sanitation and solid waste are becoming more serious to handle, different plant and animal species have become rare or extinct in some times. Climate change has impacted on architectural designs adopted as an untold climate change adaptation mechanism. New diseases are experienced and people are in serious situation of managing quality health and education (RoeschMchally, 2016). Major diseases in Shigar Town are more water borne related including diarrhea and dysentery. Valley experiencing a considerable mountain ecological change(IUCN, 2009).

\section{MATERIAL AND METHOD}

This questionnaire based study has been carried out in Shigar Valley, district Skardu of Baltistan Division, GilgitBaltistan, Pakistan during July-November, 2016. A total of two hundred interviews were conducted using the standardized instrument from different places of Shigar Valley including Ghazwapa, Trupa, Bichupa and Markunja. To ensure reliability of data, it was gathered from male and female of age fifty and above.

Climate change has been studied through community perception using following major parameters including rainfall, snowfall, glacier size, glacial melt, melting water timings, vegetation cover, monsoon flooding, biodiversity specifies richness change, temperature, precipitation, agriculture produce and productivity, floral diseases, crop sowing and harvesting periods and annual yield.

\section{RESULT}

3.1. Rainfall: According to $90 \%$ respondents rainfall has either highly increased or increased during summer in the area.Rest of $10 \%$ interviewees believe in decreased. While according to $40 \%$ rainfall during summer has either highly increased or increased as compared to $60 \%$ who believe either no change (40\%), decreased (15\%) or highly decreased $(5 \%)$ in autumn. But according to $40 \%$ respondents rainfallhas either highly decreased or decreased in winter. Rest of $(60 \%)$ interviews believe either highly increased $(10 \%)$, increased $(20 \%)$, no change $(5 \%)$, highly decreased $(5 \%)$ and unknown $(5 \%)$ in winter. According to $65 \%$ rainfall has either highly increased or increased during spring in the area. Rest of $35 \%$ believe either no change $(30 \%)$ or decreased $(5 \%)$ in spring.

3.2. Snowfall and Melt:According to $75 \%$ respondents snowfall has either highly decreased or decreased during winter in the area .Rest of $25 \%$ interviews believe either no change $(5 \%)$ and increased $(20 \%)$ in autumn. But according to $65 \%$ respondents snowfall has either highly decreased or decreased during spring in the region. Rest of $35 \%$ interviews believe either no change $(25 \%)$ and increased $(5 \%)$ and unknown $(5 \%)$ in spring. According to $100 \%$ respondents amount of snow (in feet) has either decreased or highly decreased in the area. It believe either in decreased $(85 \%)$ and highly decreased $(15 \%)$.

3.3. Temperature: According to $100 \%$ respondents'temperature has either highly increased or increased during summer in the area. While according to $40 \%$ temperature has increased during autumn in the area. Rest of $60 \%$ interviews believe either no change $(35 \%)$ or decreased $(25 \%)$ in autumn. But according to $50 \%$ respondents' temperature has highly increased (10\%) \& $(40 \%)$ increased winter. Rest of $(50 \%)$ interviews believe either no change $(25 \%)$, decreased $(20 \%)$ and $(5 \%)$ highly decreased in winter. According to $65 \%$ respondents' temperature has either highly increased or increased during summer in the area. Rest of $35 \%$ interviews believe either no change $(35 \%)$ in spring.

3.4. Monsoon Flooding:According to $85 \%$ respondents monsoon flooding has either highly increased or increased in the area. Rest of $15 \%$ interviews believe either in no change (10\%) and decreased (5\%). According to 65\% respondents pasture has decreased in the area. Rest of $35 \%$ interviews believe either in no change (25\%), increased (5\%) and unknown $(5 \%)$. While $60 \%$ village has either highly increased or increased in the region. Rest of $40 \%$ interviews believe decreased (30\%) and unknown (10\%). 

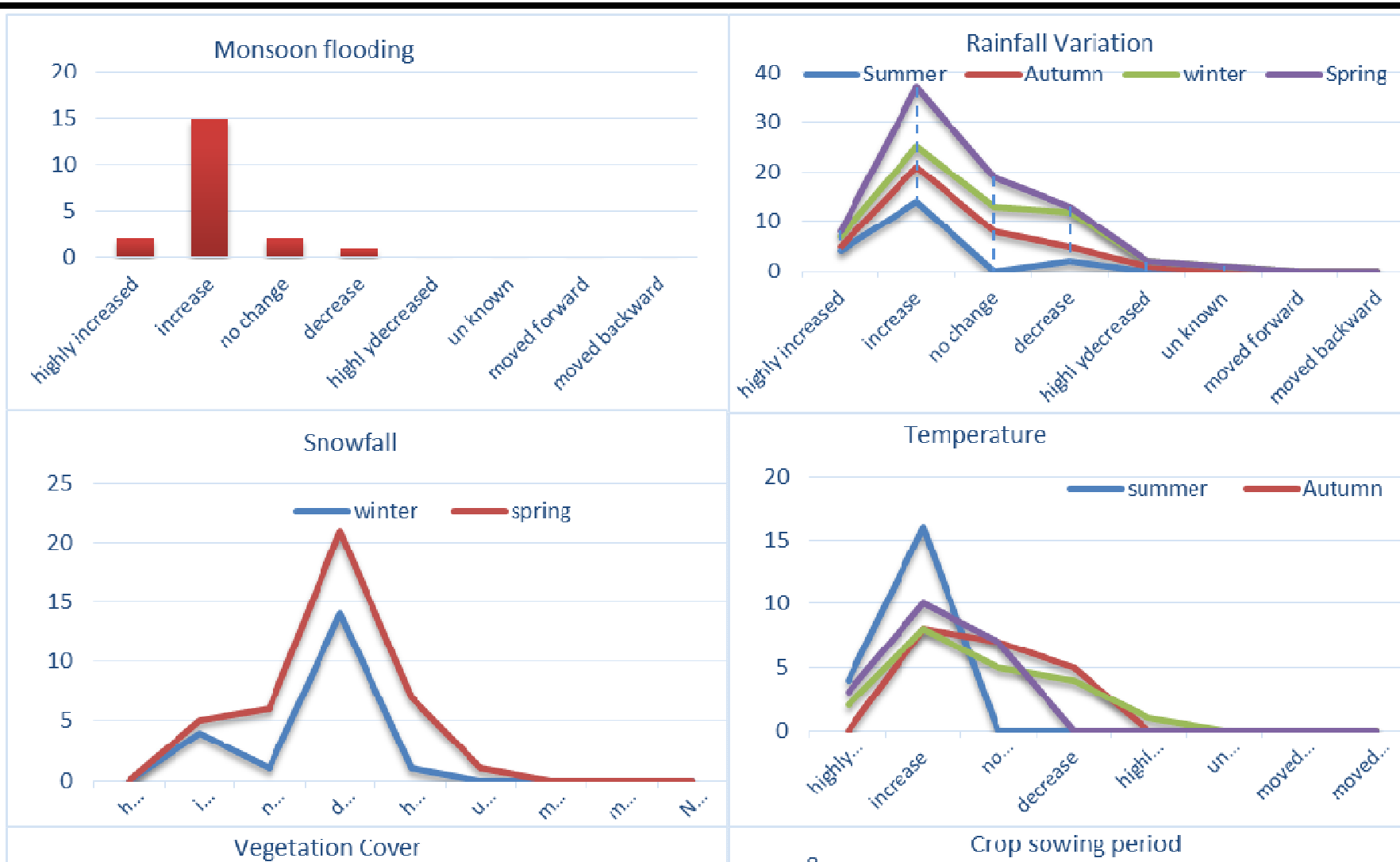

20
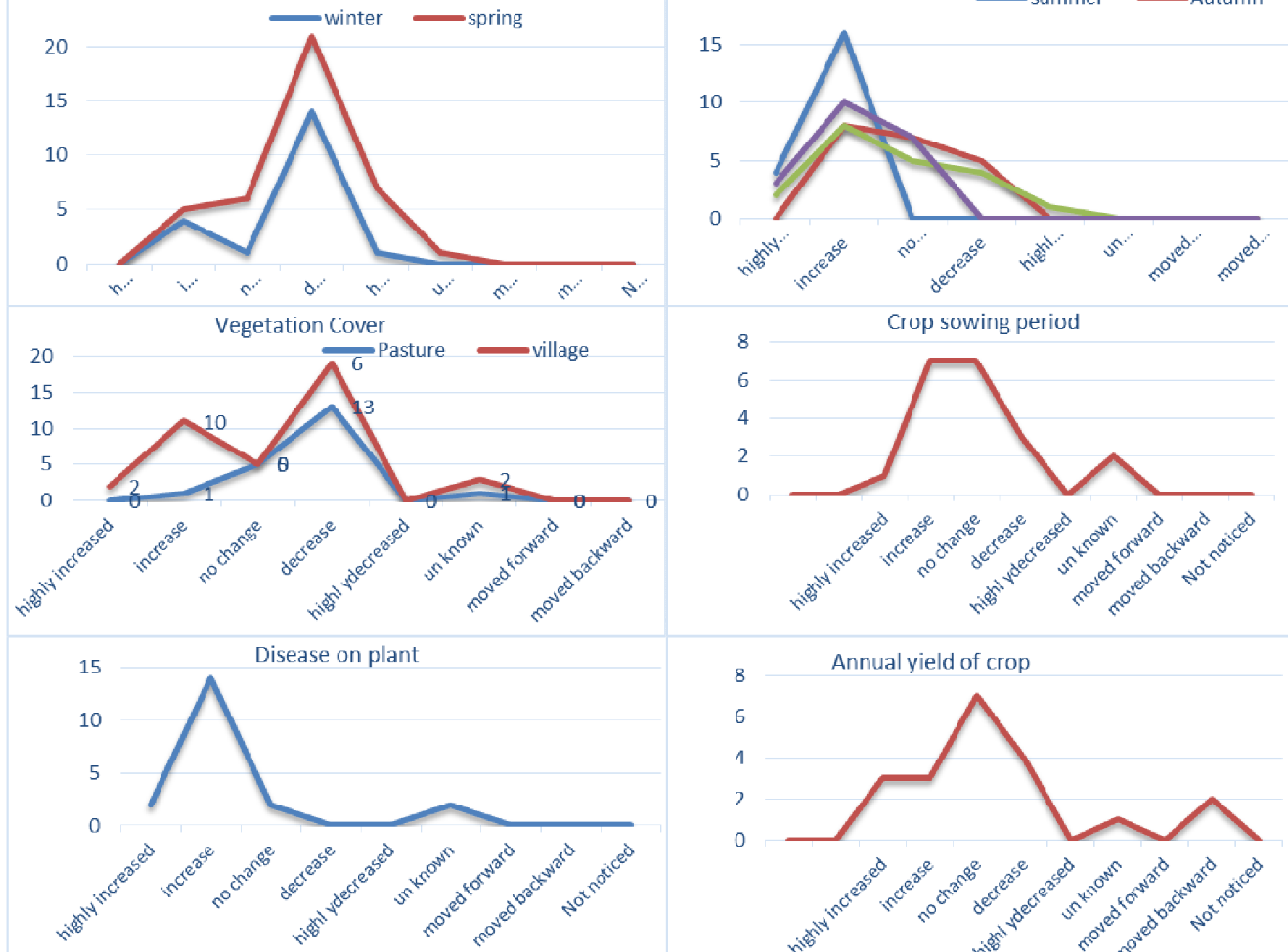

3.5. Diseases:According to $80 \%$ respondents diseasehas either highly increased or increased in the area. Rest of $20 \%$ interviews believe either in no change (10\%) and unknown (10\%).According to $40 \%$ respondents crop sowing period has either highly increased or increased in the area. Rest of

$60 \%$ interviews believe either in decreased (15\%), no change $(35 \%)$ and unknown $(10 \%)$.

3.6. Annual Yield, fruit bearing, crop harvesting and sowing period: According to $35 \%$ annual yield of crop has 


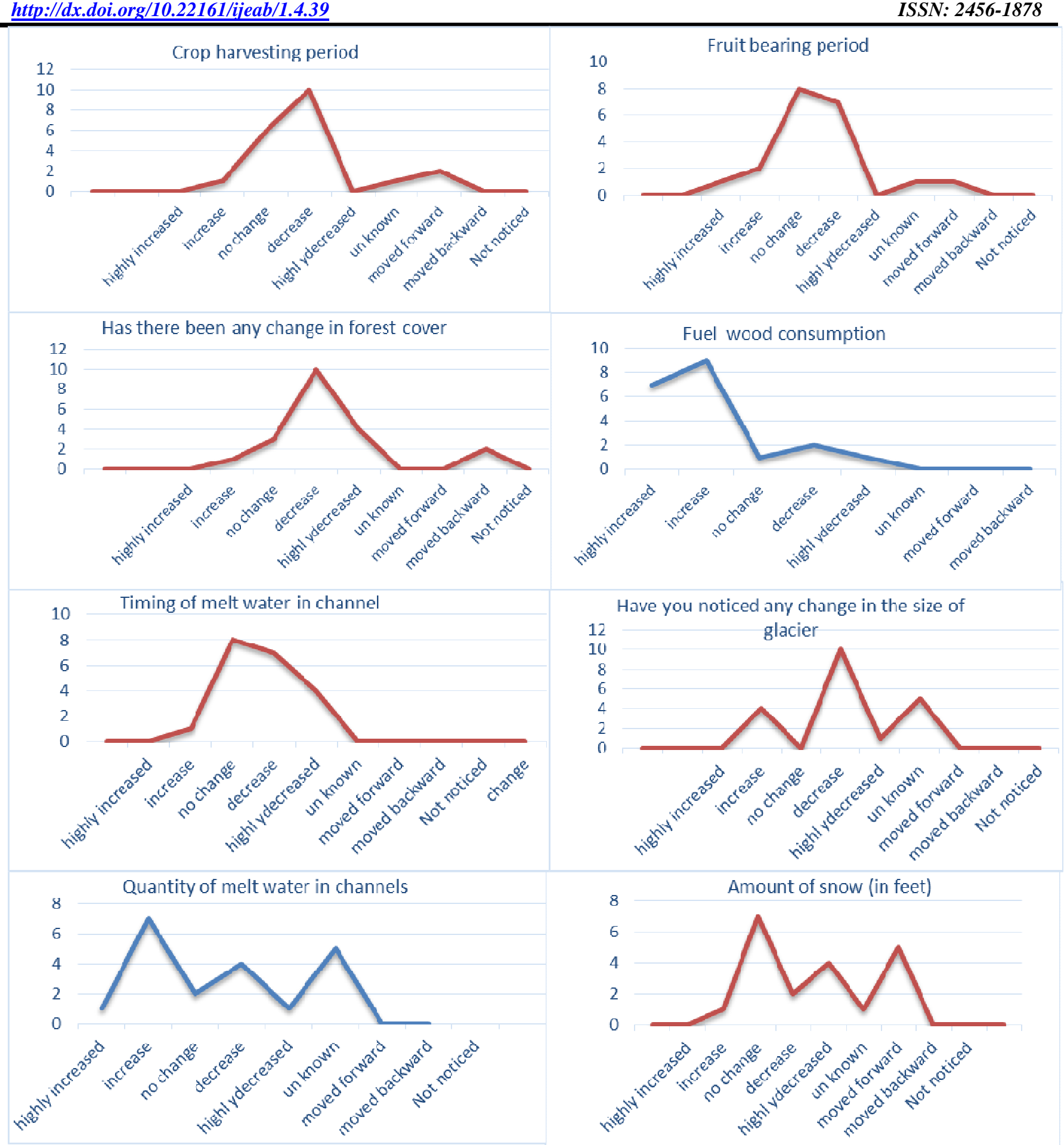

no change in the area. Rest of $65 \%$ interviews believe either in decreased (20\%), unknown (5\%) and moved backward (10\%) respectively. According to $40 \%$ respondents fruit bearing period has no change in the area. Rest of $60 \%$ interviews believe either in decreased (35\%), unknown (5\%) and moved forward (5\%), highly increased (5\%) increased (10\%) respectively. According to $50 \%$ respondents crop harvesting period has decreased in the area. Rest of $50 \%$ interviews believe either in unknown (5\%) and moved forward (10\%), no change (30\%) increased (5\%) respectively. According to $70 \%$ respondents forest cover has either decreased or highly decreased in the area. Rest of $30 \%$ interviews believe either in highly increase (5\%), nochange $(15 \%)$ and $(10 \%)$ move backward. 

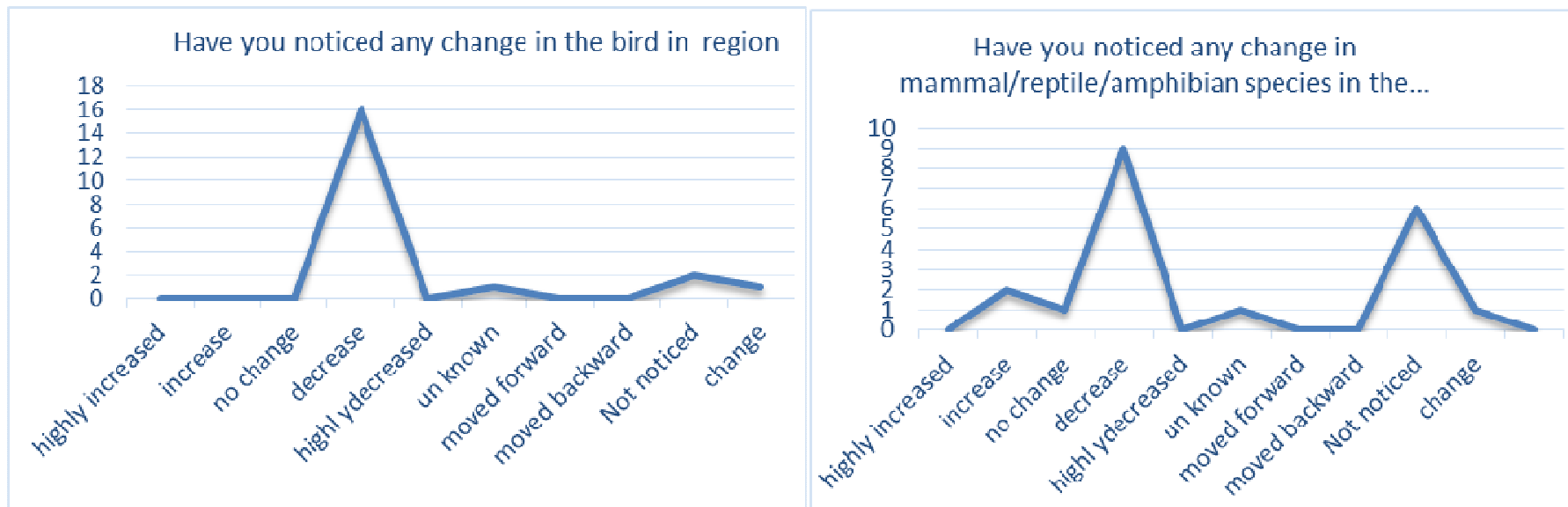

\subsection{Snow/Glacier Melt and it Quantity:According to $45 \%$} respondents timing of melt water in channel has either increased or highly increased in the area. Rest of $55 \%$ interviews believe either in decreased (20\%), and (35\%) no change.According to $55 \%$ respondents change in the size of glacier has either decreased or highly decreased in the area. Rest of $45 \%$ interviews believe either in increase $(20 \%)$, nochange (15\%) and unknown (25\%) respectively.According to $40 \%$ respondents quantity of melt water in channels has either increased or highly increased in the area. Rest of $60 \%$ interviews believe either in decreased (20\%), highly decreased (5\%), no change (10\%) and (25\%) unknown.

3.8. Fuel Consumption: According to $80 \%$ respondents fuel wood consumption has either increased or highly increased in the area. Rest of $20 \%$ interviews believe either in decreased (10\%), highly decreased $(5 \%)$ and $(5 \%)$ no change.

3.9. Biodiversity Change: According to $80 \%$ respondents noticed change in the bird spp in region has decreased in the area. Rest of $20 \%$ interviews believe either in not noticed (10\%), unknown (5\%) and (5\%) change respectively. According to $45 \%$ respondents noticed change in mammal, reptile and amphibian species in the region has decreased in the area. Rest of 55\% interviews believes either in not noticed $(30 \%)$, unknown $(5 \%)$, no change $(5 \%)$, increased $(10 \%)$ and $(5 \%)$ change respectively.

\section{ACKNOWLEDGEMENTS}

I have no words to express my feelings for my parents and my friend Rehana for her contribution and guidance. This research work has been carried out as part of my semester assignment during 2016.

\section{REFERENCES}

[1] IUCN. (2009). Community perception and change in Shigar Valley, Pakistan, A case study.

[2] Roesch-Mcnally, Gabrielle Elan.(2016). "Agricultural transformations: climate change adaptation and farmer decision making". Graduate Theses and Dissertations. Paper 15051

[3] IUNC. (2008).Environmental Management Framework for Shigar Town.skardu November 2008.IUCN Pakistan.Setember 9, 2016.

[4] Steffensen, J. P., Andersen, K. K., Bigler, M., Clausen, H. B., Dahl-Jensen, D., Fischer, H., \& MassonDelmotte, V. (2008). High-resolution Greenland ice core data show abrupt climate change happens in few years. Science, 321(5889), 680-684.

[5] Parry, M. L., Rosenzweig, C., Iglesias, A., Livermore, M., \& Fischer, G. (2004). Effects of climate change on global food production under SRES emissions and socio-economic scenarios. Global Environmental Change,14(1), 53-67.

[6] Hanjra, M. A., \& Qureshi, M. E. (2010). Global water crisis and future food security in an era of climate change. Food Policy, 35(5), 365-377.

[7] Heltberg, R., Siegel, P. B., \& Jorgensen, S. L. (2009). Addressing human vulnerability to climate change: toward a 'no-regrets' approach. Global Environmental Change, 19(1), 89-99.

[8] Gregory, P. J., Ingram, J. S., \&Brklacich, M. (2005). Climate change and food security. Philosophical Transactions of the Royal Society of London B: Biological Sciences, 360(1463), 2139-2148. 